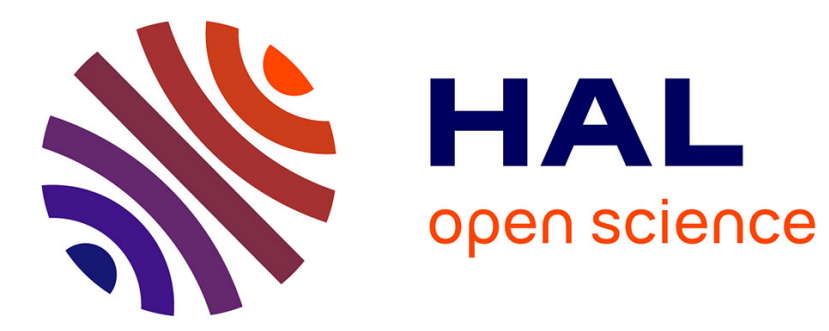

\title{
A Dashboard to Regulate Project-Based Learning
}

Christine Michel, Elise Lavoué, Laurent Piétrac

\section{To cite this version:}

Christine Michel, Elise Lavoué, Laurent Piétrac. A Dashboard to Regulate Project-Based Learning. EC-TEL 2012, Sep 2012, Saarbrücken, Germany. pp.250-263, 10.1007/978-3-642-33263-0_20 . hal00736750

\section{HAL Id: hal-00736750 \\ https://hal.science/hal-00736750}

Submitted on 12 Mar 2015

HAL is a multi-disciplinary open access archive for the deposit and dissemination of scientific research documents, whether they are published or not. The documents may come from teaching and research institutions in France or abroad, or from public or private research centers.
L'archive ouverte pluridisciplinaire HAL, est destinée au dépôt et à la diffusion de documents scientifiques de niveau recherche, publiés ou non, émanant des établissements d'enseignement et de recherche français ou étrangers, des laboratoires publics ou privés. 


\title{
A Dashboard to Regulate Project-Based Learning
}

\author{
Christine Michel $^{1,2}$, Elise Lavoué ${ }^{1,3}$, Laurent Pietrac ${ }^{1,4}$ \\ ${ }^{1}$ Université de Lyon, CNRS \\ ${ }^{2}$ INSA-Lyon, LIRIS, UMR5205, F-69621 \\ ${ }^{3}$ Université Jean Moulin Lyon 3, MAGELLAN, LIRIS, UMR5205 \\ ${ }^{4}$ INSA-Lyon, AMPERE, UMR5005, F-69621 \\ Christine.Michel@insa-lyon.fr, Elise.Lavoue@univ-lyon3.fr, Laurent.Pietrac@insa-lyon.fr
}

\begin{abstract}
In this paper, we propose the dashboards of the Pco-Vision platform to support and enhance Project-Based Learning (PBL). Based on the assumption that Self-Regulated Learning (SRL) is a major component of PBL, we have focused our attention in the design of a dashboard to enhance SRL in PBL. We describe the characteristics of PBL and show why a dashboard can help involved SRL processes, more particularly self-monitoring and self-judgment. We provide a categorization of the information to be presented on dashboards to help students involved in a PBL situation; by taking into account both the project and the learning goals. Finally we have conducted an experiment using the Pco-Vision platform with 64 students involved in a 6-months PBL course; results show that, whereas students rather use direct communication for tasks related to the self-monitoring process, the dashboard appears to be of great importance to enhance the self-judgment process, especially by presenting the information about the way of carrying out the activities.
\end{abstract}

Keywords: Self-Regulated Learning, Project-Based Learning, Dashboard.

\section{Introduction}

In this paper, we study how to support Project-Based Learning (PBL), which is a teaching and learning model that organizes learning around projects. PBL combines the project goals (the aim to achieve) and the learning goals (the knowledge to learn in the course). Actually, we observe that the implementation of PBL in engineering schools, universities or professional training do not benefit from all its capacities, because it is often action (according to the Kolb's learning cycle) which is favored to the detriment of reflection and personal experience [1]. Action involves students in the PBL situation, but is not sufficient to help them to acquire new knowledge and skills, like learning to collaborate or learning to manage a project. Our approach considers Self-Regulated Learning (SRL) as a major component of PBL to bring learners to self-reflect on their experience and to apply metacognitive skills.

Our research aims at designing a dashboard to support the SRL processes in project-based activities, by providing useful information to students. In the first part of

adfa, p. 1, 2011.

(C) Springer-Verlag Berlin Heidelberg 2011 
the paper, we study the SRL processes involved in PBL and justify the use of a dashboard to enhance self-monitoring and self-judgment processes. We base on this study to provide a categorization of the information useful for learners to regulate themselves in PBL. We then describe the software prototype Pco-Vision, which offers dashboards that present this information on the shape of indicators. In the second part, we detail the results of an exploratory study conducted in real conditions, with 64 students involved in a 6-month PBL course. We were interested in studying the utility of dashboards for students, with regard to the activities to carry out. We more particularly focused on the utility of the indicators presented on the dashboards of the PcoVision platform.

\section{State of the art}

\subsection{Project-Based Learning}

PBL is often applied in the case of complex learning, which aims to help learners acquire various linked skills or develop their behaviors [2]. Collaborative learning through project-based work promotes abstraction from experience, explanation of results, and understanding of conditions of knowledge applicability in real world situations; it also provides the experience of working in teams [3]. The main characteristic that makes PBL different from other instructional methods is its problem-centered content structure. It affects the learning and reasoning process: the teachers do not organize and assign the tasks and the learning does not consist in a simple factcollection [4]. Instead, PBL learners have to engage in a more or less inquiry process: the organization of the learning activity is only defined on a macro-schedule and students have to define actions to do to solve the problem. Moreover, the PBL situations are often carried out on a long-term, usually several months. The characteristics of PBL arouse the complexity of the learning, which requires learners to deal with the management of the actions to establish by taking into account the time and team constraints. So in a long time and collective project, learners have to regulate themselves individually and collectively.

\subsection{Self-Regulated Learning and Group Awareness}

Self-regulation can be defined as "self-generated thoughts, feelings and actions that are planned and cyclically adapted to the attainment of personal goals" [5]. Zimmermann's loop of self-regulated learning consists of three aspects: forethought, performance and self-reflection. In the social Cognitive Theory of Self-Regulation they are called self-monitoring, self-judgment, and self-reaction [6]: "Self-monitoring is the mechanism by which individuals gain information on their own performance by setting realistic goals and evaluate their progress toward them. Self-judgment involves the processes by which individuals compare their performance or actions to the personal standards they developed in a particular domain. [...] Self-reaction represents the activities undertaken to regulate actions." These processes are conven- 
tionally viewed as being predominantly individualistic [7]. According to the knowledge building model elaborated by Pata and Laanpere [8], SRL in an organizational context should also consider that in order to perform intrinsically motivated learning, learners have to align their learning activities to their organizational learning goals, the learning activities of other members of the organization and their own learning goals.

According to Carmen and Torres [9], the characteristics of self-regulated learners are self-motivation, employment of learning strategies and active participation in learning on a behavioral, motivational and metacognitive level. But it is very difficult for students to regulate their learning without help, since it requires complex skills. Unless provided with the appropriate tools, most people are not proactive enough to initiate a learning process or simply do not know how to learn [7]. The usual way to help learners to regulate their learning in a collective context is to give them group awareness tools.

The group awareness as been well defined by Buder and Bodemer [10] as knowledge about the social and collaborative environment the person is working in (e.g., knowledge about the activities, presence or participation of group members). Group awareness tools supply information to students to facilitate coordination and regulation of activities in the content space (i.e., efforts aimed at problem-solving, such as exchange of information or discussion of answers and alternatives) or the relational space (i.e., efforts to establish a positive group climate and to ensure effective and efficient collaboration [11]). They were developed in the CSCL area to foster the acquisition of group awareness, which is helpful for efficient group performance by presenting social comparison and guide for activities [12]. However, awareness tools are not meant for supporting long-term activities, by linking the activities with the goals to reach. Furthermore, according to [12], awareness approaches must be supplemented by with knowledge-related ones in order to describe an individual's state of being informed and having perceived information about others' knowledge.

\subsection{A Dashboard to Regulate Project-Based Learning}

In the context of project management, dashboards are used to present the project goals and the organization's goals and to support the collaborative work of the teams in a long-term perspective. This type of dashboard provides information resources that support distributed cognition. They are intended to provide information at a glance and to allow easy navigation to more complete information on analysis views [2]. In order to well manage a project, a dashboard must present three types of information: the state of the tasks carried out; the values of some specific characters (e.g. Coordination of resources, Scope, Time, Cost) listed by the Project Management Institute (PMI); and a performance analysis based on the relevance, effectiveness and efficiency (REE) of the resources used as compared to the results obtained [13]. When the dashboard is linked with shared workspace tools, the resources used for carrying out the tasks are directly exploited to increase awareness and cooperation in the team [14] in order to help workers to coordinate their on-going activities within the shared resources. 
In the context of Project-Based Learning (PBL) and according to an organizational approach [7], the learners need personalized information about the organization's objectives and expectations; the learning activities and achievements of co-workers; and learners' own progress with regard to their current learning goal(s). For example, Siadaty et al. [15] have developed a Learning Pal tool, which offers functionalities divided into three main sets: a) harmonization with organizational goals, b) aligning to organizational members' learning goals, and c) aligning to individual learning goals. We also think that the behavior awareness is as important as knowledge awareness in PBL, since students have to acquire various linked skills [2] and to carry out complex tasks and activities [3]. According to Scheffel et al. [16], the key to SRL is self-monitoring and self-reflecting one's own behavior. Monitoring their learning activities helps learners to become aware of their actions and that could then lead to an adjustment of their behavior.

In PBL, the monitoring process is done through the specification of goals and strategy planning. It is complex because students have to consider both the project goals (and their associated strategy) and the learning goals (and their associated strategy). The first ones are defined to support the activities to carry out to achieve the project outcomes. The second ones are defined to support the cognitive and metacognitive processes involved in the learning of project management (i.e. target academic and social skills). The formalization of these goals is necessary due to the time and team constraints. The results of the actions have to be presented to the team in order to help the project management and to help each member to do the self-monitoring and selfjudgment on the academic and social skills applied. Our work relies on the assumption that the use of a dashboard can help these processes.

\section{A dashboard for students in PBL situations}

\subsection{Information to present on a dashboard in PBL situations}

In this part, we first provide a categorization of the information useful for learners to regulate themselves in PBL. It is based on both project management systems and group awareness issues. We then describe the Pco-Vision platform we have developed to support the SRL processes in a PBL course. We distinguish two types of information: (1) the information about the individuals' and groups' goals, which direct the activities and (2) the information about the activities: the way of carrying out them and their results.

\section{Information about goals}

- The project goals. The project group defines the project goals into the master plan. With regard to the PMI recommendations, most useful information is about project integration, human resource, time and scope. It can be represented by planned tasks, to which human resources are allocated. Information about pre-identified 
risks is also useful. So the project goals information is really closed to information managed with classical project management tools.

- The learning goals. The learning goals are the knowledge to acquire. In the context of PBL, there are two types of learning goals. The course learning goals are the knowledge required to achieve the course. They are described into the curriculum of the course and correspond to pre-defined evaluation rules. The project learning goals are the knowledge necessary to achieve the project. When the goal is different for each project, each group has its own knowledge to acquire (e.g. about the subject of the project or the programming language to use). The members of a group could also have different learning goals, since they have different tasks to achieve.

Information about the activities. In order to help the self-monitoring process and to reinforce the learners' motivation, we advise to present both information about the way the activities are carried out and their results.

- The way of carrying out the activities. The way of carrying out the activities relates to the learners' and groups' behaviors and state of mind during the project. On an objective way, the behavior and the level of motivation can be represented for instance by the time spent working on the project (individually and collectively), the social organization (the members who work together), or the modalities of work (presence or distance, individual or collective). On a more subjective way, the way of carrying out the project can be described by the level of motivation and the state of mind expressed by students during their work: satisfaction of themselves, feeling of efficacy and efficiency or their situation within their group.

- The results of the activities. With regards to the goals, the results of the activities relate, on the one hand, to the progress in the project and, on the other hand, to the level of knowledge acquired. These results have to be presented taking into account the target level of achievement defined for each goal. Furthermore, the results concern different actors: some are defined for each member individually and others for the whole project group.

In this categorization, we make the hypothesis that the awareness of the project goals compared to the results of the activities will help the self-monitoring of the skills applied to achieve the project. On the same way, the awareness of the learning goals compared to the results of the activities will help the self-monitoring of the skills applied to achieve the course. The self-judgment process will be supported by information about the way of carrying out the activities. The motivation and behavior of the team can be viewed as an indirect judgment of the pairs. The modality of work or time spent can be viewed as a standard of comparison. Finally, the whole information gives to student the possibility to make causality links between goals, actions and results. It so can help the self-reaction process. This is especially helpful to build complex skills that require an evolution of behavior. 


\subsection{The dashboards of the Pco-Vision platform}

General presentation. We adopt an iterative and participatory design approach to develop a platform to support PBL. The software prototype Pco-Vision is the result of a second development cycle and is based on a paper prototype named MESHAT [2]. It has been designed mainly to test the utility of the information presented on dashboards in a PBL course. Pco-Vision is a web-based platform, which offers several functionalities thanks to five drop-down menus (see Fig. 1). (a) A home menu provides a video demonstration to help students to use the platform. (b) A data capture menu offers several data entry forms to students. (c) A dashboards menu gives access to an individual and a group awareness project tools (dashboards). (d) A collaboration menu gives access to a blog and an agenda for the group. (e) A documentation menu gives access to resources useful for the project (e.g. models of document) and for the course achievement (e.g. a learning contract).

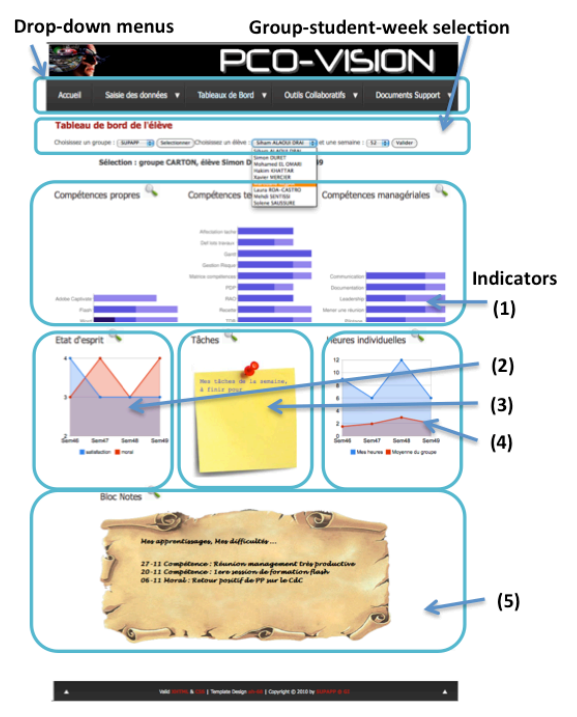

Fig. 1. Individual dashboard with five numbered indicators.

Dashboards. Pco-Vision offers two dashboards: a collective dashboard for the group and an individual dashboard for each student. Students can click on indicators to access an analytical view.

- The individual dashboard. The individual dashboard (see Fig. 1) offers to students an overview of their activities thanks to five indicators: (1) their level for the knowledge they have to acquire, in comparison with the target level defined in the master plan, (2) their state of mind during the last four weeks, on the shape of two curves (morale and satisfaction), (3) the tasks to do, on the shape of a post-it note, (4) the individual working time in comparison with the collective working time, on the last four weeks (two different curves), (5) the key events that students note (like in a blog). 
- The project group dashboard. The group dashboard presents six indicators: (1) the workload (the working time of the group, with regards to the planned tasks), (2) the ratio of individual to collective work, (3) the level of knowledge acquired with regards to the defined target level, (4) the problems that occurred and the number of times, (5) the state of mind (mean, minimum, maximum and deviation of the level of satisfaction of the members), (6) the progress of the tasks.

In order to support the analytical process of reflexive behavior understanding, students can explore information about the way they are doing activities [17]. For example on Fig. 2, students can view the global evolution of their morale and satisfaction during the first months of the project, and navigate dynamically on this view.

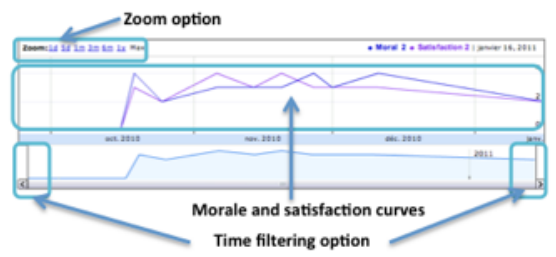

Fig. 2. Global indicator for morale and satisfaction.

The intended use of the dashboards. The dashboards of the Pco-Vision platform could be used when the project group has finished to define the goal of the project (the solution they propose to solve the problem) and the broad outline of the project plan (formalized in the master plan document). First, the project manager could report the planed organization into the dashboards: the tasks to do (list, affectations and dates) and the target knowledge of the members. Then, the dashboards could be opened to all the members and to the tutors assigned to monitor them.

\section{An exploratory study of dashboards for PBL}

\subsection{Context and participants}

The participants on this study included a convenience sample of 64 students from an engineer school in France, registered on a 6-month PBL course. The students worked on a self-regulated way by group of 8-9 students, on a specific real industrial problem. The learning goals of the course were to learn to manage a project and to learn to collaborate. This course is conducted since 12 years and each year the students are asked to develop their own dashboard in order to coordinate the tasks and the team. As the use of a dashboard is already integrated into the framework of this course, we chose this context to study the use of a dashboard for self-regulated learning.

The students of the experimental group $(\mathrm{n}=24)$ used the dashboards of Pco-Vision during the project. In the paper, this group is named "Pco-Vision group". The students of the control group $(n=40)$ used a dashboard that they have developed by their own, mainly on spreadsheets. Concerning the PBL course, all the students followed the 
same rules and had the same evaluation criteria. The groups had their own tutor that they met every week in order to take advices. They also each had a dedicated project room during the 6 months in order to work by group.

\subsection{Data collection and analysis}

The results are based on a quantitative statistical analysis of questionnaires. At the end of the course, all the students $(n=64)$ answered a questionnaire composed of 28 questions. First questions concern the utility of the dashboard in the PBL context and is measured by yes/no questions. Other questions concern the relevance of the use of dashboards in order to manage some specific tasks and the other means the students used to manage their project. These questions were measured according to a Lickert scale (1 to 4). The students from the Pco-Vision group $(n=24)$ answered an additional questionnaire about the general design of Pco-Vision and the relevance of the indicators presented on Pco-Vision. This questionnaire is composed of 24 questions measured according to a yes/no scale (11 questions) and a Lickert scale (1 to 4 ) (13 questions). This study aims to answer the following questions:

- Is a dashboard useful in the context of a PBL course?

- How often the dashboard and other external means are used to support individual and/or group activity regulation? We more particularly studied two types of regulation processes: self-monitoring and self-judgment.

- Amongst the indicators presented on the dashboards of Pco-Vision, which were the more frequently used by the students?

The questions related to the use of a dashboard (and external tools) for some tasks are intended to measure their relevance for these tasks. As recommended in [18], they are also intended to measure the individual perception of cognitive or metacognitive processes involved and so give information about the student's SRL aptitudes. The two distinct groups (Pco-Vision group and control group) allow us to study the impact of the use of a given dashboard (in Pco-Vision) on the students' SRL aptitudes, in comparison with the students who develop their own dashboard.

\section{$5 \quad$ Results}

\subsection{General utility of a dashboard in a PBL course}

Utility of a dashboard. The students rather agree with using a dashboard in the context of the course (see Table 1). For the majority of them, the context of the course (in university and in presence) and the size of the groups (only 8 or 9 students) do not limit the relevance of the use of dashboards. We make the assumption that the large number of "no answers" involves that the students that had Pco-Vision did not feel concerned by these questions. 
Table 1. Utility and limits of the use of a dashboard in the study (Pco-vision $v s$ control group)

\begin{tabular}{lllll}
\hline Utility and limit of dashboard & & No & No & Yes \\
\hline answer & & & \\
\hline Utility of a dashboard & pco & $1.00 \%$ & $8.33 \%$ & $\mathbf{8 7 . 5 0 \%}$ \\
for the course & cont & $10.00 \%$ & $10.00 \%$ & $\mathbf{6 5 . 0 0 \%}$ \\
Limits related to the & pco & $91.67 \%$ & $0.00 \%$ & $\mathbf{8 . 3 3} \%$ \\
size of the team & cont & $0.00 \%$ & $92.50 \%$ & $\mathbf{7 . 5 0} \%$ \\
Limits related to the & pco & $91.67 \%$ & $0.00 \%$ & $\mathbf{8 . 3 3} \%$ \\
academic context & cont & $0.00 \%$ & $95.00 \%$ & $\mathbf{5 . 0 0 \%}$ \\
\hline
\end{tabular}

As a major result of the analysis work, Tables 2 and 3 show the tasks carried out by both groups of students with their group and individual dashboards. We observe a significant difference between the responses of the two groups. On the one hand, as the responses of the control group are almost identically distributed, we cannot identify a strong tendency in their use of their dashboard. Furthemore, we observe a large part of "no answer" responses in the control group, which means that the students did not understood or did not felt concerned. On the other hand, we can identify a tendency in the use of Pco-Vision. The students mostly used punctually Pco-Vision for the self-monitoring tasks we asked them in the questionnaire. We also observe that they more often used Pco-Vision in order to support their self-judgment individually (by checking their working time) and within their group (by checking the others' tasks, working time, moral and satisfaction). We deduce that having Pco-Vision has encouraged the students to have self-regulation processes, especially self-judgment.

Table 2. Frequency of use of the dashboard for the group work (Pco-Vision vs control group)

\begin{tabular}{|c|c|c|c|c|c|c|}
\hline Tasks related to group work & & $\begin{array}{l}\text { No } \\
\text { answer }\end{array}$ & $\begin{array}{l}\text { Never } \\
\text { Used }\end{array}$ & $\begin{array}{l}\text { Punc- } \\
\text { tually } \\
\text { Used }\end{array}$ & $\begin{array}{l}\text { Often } \\
\text { Used }\end{array}$ & $\begin{array}{l}\text { Fre- } \\
\text { quently } \\
\text { used }\end{array}$ \\
\hline \multicolumn{7}{|l|}{ Self-monitoring process } \\
\hline \multirow[t]{2}{*}{ Define de director plan } & pco & $4.17 \%$ & $12.50 \%$ & $70.83 \%$ & $12.50 \%$ & $0.00 \%$ \\
\hline & cont & $32.50 \%$ & $47.50 \%$ & $12.50 \%$ & $7.50 \%$ & $0.00 \%$ \\
\hline \multirow[t]{2}{*}{ Adapt the director plan } & pco & $4.17 \%$ & $33.33 \%$ & $62.50 \%$ & $0.00 \%$ & $0.00 \%$ \\
\hline & cont & $32.50 \%$ & $45.00 \%$ & $12.50 \%$ & $7.50 \%$ & $2.50 \%$ \\
\hline Coordinate the progress & pco & $4.17 \%$ & $33.33 \%$ & $62.50 \%$ & $0.00 \%$ & $0.00 \%$ \\
\hline of the tasks & cont & $27.50 \%$ & $12.50 \%$ & $25.00 \%$ & $15.00 \%$ & $20.00 \%$ \\
\hline Coordinate the work & pco & $4.17 \%$ & $33.33 \%$ & $62.50 \%$ & $0.00 \%$ & $0.00 \%$ \\
\hline of the group & cont & $27.50 \%$ & $20.00 \%$ & $25.00 \%$ & $10.00 \%$ & $17.50 \%$ \\
\hline \multicolumn{7}{|l|}{ Self-judgment process } \\
\hline \multirow[t]{2}{*}{ Check the others' tasks } & pco & $4.17 \%$ & $33.33 \%$ & $45.83 \%$ & $12.50 \%$ & $4.17 \%$ \\
\hline & cont & $30.00 \%$ & $25.00 \%$ & $25.00 \%$ & $12.50 \%$ & $7.50 \%$ \\
\hline Check the others' working & pco & $4.17 \%$ & $20.83 \%$ & $41.67 \%$ & $25.00 \%$ & $8.33 \%$ \\
\hline time & cont & $30.00 \%$ & $15.00 \%$ & $17.50 \%$ & $22.50 \%$ & $15.00 \%$ \\
\hline Check the moral and & pco & $4.17 \%$ & $12.50 \%$ & $50.00 \%$ & $16.67 \%$ & $16.67 \%$ \\
\hline satisfaction of the others & cont & $27.50 \%$ & $17.50 \%$ & $15.00 \%$ & $22.50 \%$ & $17.50 \%$ \\
\hline
\end{tabular}


Table 3. Frequency of use of the dashboard for individual work (Pco-Vision $v s$ control group)

\begin{tabular}{lllllll}
\hline & & $\begin{array}{l}\text { No } \\
\text { an- } \\
\text { swer }\end{array}$ & $\begin{array}{l}\text { Never } \\
\text { Used }\end{array}$ & $\begin{array}{l}\text { Punc- } \\
\text { tually } \\
\text { Used }\end{array}$ & $\begin{array}{l}\text { Often } \\
\text { Used }\end{array}$ & $\begin{array}{l}\text { Fre- } \\
\text { quent- } \\
\text { ly } \\
\text { used }\end{array}$ \\
\hline Self-monitoring process & & & & & & \\
Check my tasks to do & pco & $4.17 \%$ & $33.33 \%$ & $\mathbf{5 8 . 3 3 \%}$ & $4.17 \%$ & $0.00 \%$ \\
& cont & $\mathbf{2 5 . 0 0 \%}$ & $45.00 \%$ & $10.00 \%$ & $7.50 \%$ & $12.50 \%$ \\
Regulate my way of work & pco & $4.17 \%$ & $29.17 \%$ & $\mathbf{5 8 . 3 3 \%}$ & $8.33 \%$ & $0.00 \%$ \\
& cont & $\mathbf{2 7 . 5 0 \%}$ & $32.50 \%$ & $10.00 \%$ & $10.00 \%$ & $20.00 \%$ \\
Analyze the way the & pco & $4.17 \%$ & $29.17 \%$ & $\mathbf{5 8 . 3 3 \%}$ & $4.17 \%$ & $4.17 \%$ \\
project is realized & cont & $\mathbf{3 0 . 0 0 \%}$ & $35.00 \%$ & $22.50 \%$ & $7.50 \%$ & $5.00 \%$ \\
Analyze my way of & pco & $4.17 \%$ & $29.17 \%$ & $\mathbf{6 2 . 5 0} \%$ & $0.00 \%$ & $4.17 \%$ \\
work in team & cont & $\mathbf{3 2 . 5 0 \%}$ & $30.00 \%$ & $20.00 \%$ & $10.00 \%$ & $7.50 \%$ \\
\hline Self-judgment process & & & & & & \\
Check my working time & pco & $4.17 \%$ & $12.50 \%$ & $\mathbf{2 9 . 1 7 \%}$ & $\mathbf{4 1 . 6 7 \%}$ & $\mathbf{1 2 . 5 0 \%}$ \\
& cont & $25.00 \%$ & $10.00 \%$ & $15.00 \%$ & $37.50 \%$ & $12.50 \%$ \\
\hline
\end{tabular}

The association of tools with dashboards. We questioned the students about the other means or tools they used, in association with their dashboards. Both groups have regularly used oral discussions to plan the tasks and to monitor the progress of the project. To keep tracks of the discussions, some students (principally in the PcoVision group) have entered the results of the discussions into the dashboards and have made synthesis. Both groups used communication tools (email and SMS) to organize the collaboration.

We observe significant differences between the two groups in the use of tools: the students of the Pco-Vision group have more often used planning and collaboration tools than the students of the control group. In order to plan the tasks, most of the students of the Pco-Vision group used a paper Gantt chart, and about half of them also used a project management tool, an electronic Gantt chart and a shared calendar. About half of the students of the Pco-Vision group also used other platforms (like googledoc) and a chat tool to collaborate. Only few students of the control group used these planning and collaboration tools.

Table 4. External means used to plan and monitor the tasks and to collaborate (Pco-Vision vs control group)

\begin{tabular}{llll|lll}
\hline & \multicolumn{3}{c|}{ Pco-Vision Group } & \multicolumn{3}{c}{ Control Group } \\
\hline External means used & $\begin{array}{l}\text { No } \\
\text { answer }\end{array}$ & No & Yes & $\begin{array}{l}\text { No } \\
\text { answer }\end{array}$ & No & Yes \\
\hline To plan the work & & & & & & \\
Project management tool & $12.50 \%$ & $41.67 \%$ & $45.83 \%$ & $0.00 \%$ & $\mathbf{7 0 . 0 0 \%}$ & $30.00 \%$ \\
Electronic Gantt chart & $12.50 \%$ & $41.67 \%$ & $45.83 \%$ & $0.00 \%$ & $\mathbf{7 5 . 0 0 \%}$ & $25.00 \%$ \\
Paper Gantt chart & $8.33 \%$ & $20.83 \%$ & $\mathbf{7 0 . 8 3} \%$ & $0.00 \%$ & $\mathbf{7 2 . 5 0 \%}$ & $27.50 \%$ \\
Online shared calendar & $12.50 \%$ & $41.67 \%$ & $45.83 \%$ & $0.00 \%$ & $\mathbf{8 0 . 0 0 \%}$ & $20.00 \%$
\end{tabular}




\begin{tabular}{llll|lll}
$\begin{array}{l}\text { Face to face discussions } \\
\text { Discussions formalized } \\
\text { into the dashboard }\end{array}$ & $4.17 \%$ & $0.00 \%$ & $\mathbf{9 5 . 8 3} \%$ & $0.00 \%$ & $40.00 \%$ & $\mathbf{6 0 . 0 0 \%}$ \\
\hline $\begin{array}{l}\text { To monitor the project progress } \\
\text { Face-to-face discussions }\end{array}$ & $12.50 \%$ & $25.00 \%$ & $\mathbf{6 2 . 5 0} \%$ & $0.00 \%$ & $55.00 \%$ & $\mathbf{4 5 . 0 0 \%}$ \\
Synthesis of a team member & $0.00 \%$ & $0.00 \%$ & $\mathbf{1 0 0} \%$ & $0.00 \%$ & $40.00 \%$ & $\mathbf{6 0 . 0 0 \%}$ \\
\hline To organize the collaboration & $12.50 \%$ & $16.67 \%$ & $70.83 \%$ & $0.00 \%$ & $55.00 \%$ & $45.00 \%$ \\
\hline $\begin{array}{l}\text { Email (to send files) } \\
\text { Other platforms (googledocs) }\end{array}$ & $0.00 \%$ & $0.00 \%$ & $\mathbf{1 0 0} \%$ & $0.00 \%$ & $27.50 \%$ & $\mathbf{7 2 . 5 0} \%$ \\
Chat & $8.33 \%$ & $41.67 \%$ & $50.00 \%$ & $0.00 \%$ & $\mathbf{7 2 . 5 0 \%}$ & $27.50 \%$ \\
SMS & $16.67 \%$ & $37.50 \%$ & $45.83 \%$ & $0.00 \%$ & $\mathbf{9 7 . 5 0 \%}$ & $2.50 \%$ \\
\hline
\end{tabular}

\subsection{Specific analysis of the use of Pco-Vision}

General evaluation. According to the results presented in Table 5, Pco-Vision was seen as a constraint with limited benefit to the students' activity. Approximately half of the students consider that the group dashboard and the individual one (see Fig. 1) are adapted. Most useful indicators are synthesis ones (i.e. presented on the overview of the dashboard). Indeed, only few students have used dynamic indicators to see an analytical view (see Fig. 2). The indicators are globally considered coherent and rather useful but not sufficient. More precisely, the students consider indicators not very relevant and that they do not well reflect the reality. These results could be partly explained by an insufficient general design of Pco-Vision: the information loading process is low and must be improved; the data input process is based on a manual reporting activity (done one time per week) and so the data may not be very accurate, even missing.

Table 5. General evaluation of Pco-Vision

\begin{tabular}{llll}
\hline & $\begin{array}{l}\text { No } \\
\text { answer }\end{array}$ & No & Yes \\
\hline General statement about pcovision & & & \\
Seen as a constraint & $8.3 \%$ & $37.5 \%$ & $54.2 \%$ \\
Have given benefice & $20.8 \%$ & $50.0 \%$ & $29.2 \%$ \\
Group Dashboard was adapted & $4.2 \%$ & $45.8 \%$ & $\mathbf{5 0 . 0} \%$ \\
Individual Dashboard was adapted & $4.2 \%$ & $41.7 \%$ & $\mathbf{5 4 . 2 \%}$ \\
\hline Evaluation of Indicators & & & \\
Coherent & $4.2 \%$ & $29.2 \%$ & $\mathbf{6 6 . 7} \%$ \\
Relevant & $4.2 \%$ & $\mathbf{5 8 . 3 \%}$ & $37.5 \%$ \\
Reflect the real activity & $4.2 \%$ & $\mathbf{5 8 . 3} \%$ & $37.5 \%$ \\
Useful & $4.2 \%$ & $50.0 \%$ & $45.8 \%$ \\
Sufficient & $12.5 \%$ & $\mathbf{6 6 . 7 \%}$ & $20.8 \%$ \\
Use of synthesis indicators & $4.2 \%$ & $37.5 \%$ & $\mathbf{5 8 . 3} \%$ \\
Use of dynamic indicators & $8.3 \%$ & $\mathbf{7 5 . 0} \%$ & $16.7 \%$ \\
\hline
\end{tabular}


Usefulness of indicators. The most used indicators are about the way of carrying out the activities. More precisely, the students mainly used Pco-Vision to see the state of mind (morale and satisfaction) of the group, the workload of the group, the ratio of individual to collective work and their individual working time. The less used indicators are those related to the results of the activities: the level of knowledge and skills acquired (at the individual and group level) and the progress in the project. In connection with the hypothesis made in section 3.1, we deduce that the students mainly used the information that helps the self-judgment process than the information supporting the self-monitoring process.

Table 6. Usefulness of the Pco-vision indicators

\begin{tabular}{llllll}
\hline Pco-Vision Indicators & No & $\begin{array}{l}\text { Never } \\
\text { Unswer }\end{array}$ & $\begin{array}{l}\text { Punctu- } \\
\text { ally } \\
\text { Used }\end{array}$ & $\begin{array}{l}\text { Often } \\
\text { Used }\end{array}$ & $\begin{array}{l}\text { Fre- } \\
\text { quently } \\
\text { used }\end{array}$ \\
\hline Group dashboard & & & & & \\
Workload & $4.17 \%$ & $29.17 \%$ & $29.17 \%$ & $\mathbf{2 5 . 0 0 \%}$ & $\mathbf{1 2 . 5 0 \%}$ \\
Ratio of individual to collective work & $4.17 \%$ & $37.50 \%$ & $20.83 \%$ & $\mathbf{2 9 . 1 7 \%}$ & $\mathbf{8 . 3 3 \%}$ \\
Level of knowledge acquired & $0.00 \%$ & $\mathbf{6 6 . 6 7 \%}$ & $\mathbf{2 0 . 8 3 \%}$ & $12.50 \%$ & $0.00 \%$ \\
Problems & $0.00 \%$ & $54.17 \%$ & $29.17 \%$ & $12.50 \%$ & $4.17 \%$ \\
State of mind & $0.00 \%$ & $20.83 \%$ & $33.33 \%$ & $\mathbf{3 3 . 3 3 \%}$ & $\mathbf{1 2 . 5 0 \%}$ \\
Tasks achievement progress & $0.00 \%$ & $\mathbf{5 4 . 1 7 \%}$ & $\mathbf{3 3 . 3 3 \%}$ & $12.50 \%$ & $0.00 \%$ \\
\hline Individual dashboard & & & & & \\
Skills required for project achievement & $8.33 \%$ & $\mathbf{2 9 . 1 7 \%}$ & $\mathbf{4 1 . 6 7 \%}$ & $20.83 \%$ & $0.00 \%$ \\
Level of knowledge (technical skills) & $8.33 \%$ & $\mathbf{2 9 . 1 7 \%}$ & $\mathbf{5 0 . 0 0 \%}$ & $12.50 \%$ & $0.00 \%$ \\
Level of knowledge (social skills) & $8.33 \%$ & $\mathbf{3 7 . 5 0 \%}$ & $\mathbf{5 0 . 0 0 \%}$ & $4.17 \%$ & $0.00 \%$ \\
State of mind & $8.33 \%$ & $20.83 \%$ & $45.83 \%$ & $20.83 \%$ & $4.17 \%$ \\
Tasks to do & $8.33 \%$ & $37.50 \%$ & $25.00 \%$ & $25.00 \%$ & $4.17 \%$ \\
Working time & $8.33 \%$ & $29.17 \%$ & $8.33 \%$ & $\mathbf{4 1 . 6 7 \%}$ & $\mathbf{1 2 . 5 0 \%}$ \\
Self-notes, keys events & $8.33 \%$ & $41.67 \%$ & $25.00 \%$ & $16.67 \%$ & $8.33 \%$ \\
\hline
\end{tabular}

\section{Discussion and conclusions}

In this paper, we have first provided a categorization of the information to present on a dashboard to enhance Self-Regulation Learning (SRL) processes in a Project-Based Learning (PBL) course. This categorization distinguishes the information about goals (project and learning goals) and the information about the activities (the way of carrying out them and their results). We based on this categorization to design the dashboards of the Pco-Vision software prototype that has been used by 64 students in a PBL course during six months. We conducted a study in the context of this course by the way of two questionnaires and we think that the results of the study have implication for the design and the integration of a dashboard in a PBL course.

The students agree with the importance of using a dashboard in their PBL course. However, the students with Pco-Vision felt the use of the dashboard as a constraint with limited benefice to their activity. But, although Pco-Vision has design problems 
that explain a rather negative opinion of the students, the results allowed us to identify a positive tendency in the use of the dashboard for some specific tasks that help the self-monitoring and self-judgment processes. We so first deduce that having PcoVision has encouraged the students to apply self-regulation processes.

The dashboard has been mainly used to support the self-judgment process, thanks to the information on the way of carrying out the individual and group activities, especially the working time and the state of mind. The students also used the dashboard to compare themselves or to check if their involvement in the project (quantity of work) was visible.

The dashboard has been little used to support tasks related to the self-monitoring process. Indeed, the students prefer direct communication (face-to-face, Email, SMS) or tangible tools (paper support) to plan the tasks, to monitor the progress of the project and to organize the collaboration within the team. However, we observed that the students of the Pco-Vision group are more inclined than those of the control group to use instrumented tools, more particularly planning and collaboration tools,

As a perspective, we will improve the design of the dashboards of Pco-vision, so as to facilitate their use. Indeed, the students have trouble reporting each week the data related to the way they carry out their activities and so consider that the indicators do not well reflect the reality. Moreover, the students did not succeed in using knowledge indicators (the level for the knowledge to acquire) or deep indicators presented in analytical views.

We make some hypothesis to explain these results and to determine our future work. We think that the presentation of the indicators on the dashboards has to be rethought, so as to help their use to support complex tasks (monitor the collaborative work, support metacognitive process) and so enhance self-regulation. For instance, we will use more spatial or temporal information views in order to improve the work with indicators during the monitoring and reacting steps. We thing also useful to offer other interaction functions of flexible display layouts [15] in order to let students manipulate indicators, choose their presentation and modify their view-size and position according to their importance and weight. Finally, we will improve the data input process, for instance by offering contextualized and flexible data input interfaces centered on each unit of task carried out. We will also automate a part of the data input process by linking the dashboards with other tools used to carry out the project (e.g. Gantt chart).

\section{References}

1. Thomas, J., Mengel, T.: Preparing project managers to deal with complexity - Advanced project management education. International Journal of Project Management. 26, 304-315 (2008).

2. Michel, C., Lavoué, E.: KM and Web 2.0 Methods for Project-Based Learning. MEShaT: a Monitoring and Experience Sharing Tool. Multiple Perspectives on Problem Solving and Learning in the Digital Age. p. 49-66. Ifenthaler D., Isaias P., Spector J.M., Kinshuk, Sampson D., Heidelberg (2011). 
3. Jeremic, Z., Jovanovic, J., Gasevic, D.: Semantically-Enabled Project-Based Collaborative Learning of Software Patterns. Advanced Learning Technologies, IEEE International Conference on. p. 569-571. IEEE Computer Society, Los Alamitos, CA, USA (2009).

4. Hung, W.: The 9-step problem design process for problem-based learning: Application of the 3C3R model. Educational Research Review. 4, 118-141 (2009).

5. Zimmerman, B.: Attaining self-regulation: A social cognitive perspective. Handbook of self-regulation. p. 13-40 (2000).

6. Gravill, J., Compeau, D.: Self-regulated learning strategies and software training. Information \& Management. 45, 288-296 (2008).

7. Littlejohn, A., Margaryan, A., Milligan, C.: Charting Collective Knowledge: Supporting Self-Regulated Learning in the Workplace. Ninth IEEE International Conference on Advanced Learning Technologies, 2009. ICALT 2009. p. 208-212. IEEE (2009).

8. Pata, K., Laanpere, M.: Supporting Cross-Institutional Knowledge-Building with Web 2.0 Enhanced Digital Portfolios. Eighth IEEE International Conference on Advanced Learning Technologies, 2008. ICALT '08. p. 798-800. IEEE (2008).

9. Carmen, M., Torres, G.: Self-Regulated Learning: Current and Future Directions. Educational Psychology. 2, 1-34 (2004).

10. Buder, J., Bodemer, D.: Group Awareness Tools for Controversial CSCL Discussions: Dissociating Rating Effects and Visualized Feedback Effects. 9th International Conference on Computer Supported Collaborative Learning (CSCL2011). p. 358-365. , Hong Kong (2011).

11. Janssen, J., Erkens, G., Kirschner, P.A.: Group awareness tools: It's what you do with it that matters. Computers in Human Behavior. 27, 1046-1058 (2011).

12. Engelmann, T., Dehler, J., Bodemer, D., Buder, J.: Knowledge awareness in CSCL: A psychological perspective. Comput. Hum. Behav. 25, 949-960 (2009).

13. Marques, G., Gourc, D., Lauras, M.: Multi-criteria performance analysis for decision making in project management. International Journal of Project Management. 29, 10571069 (2011).

14. Treude, C., Storey, M.-A.: Awareness 2.0: staying aware of projects, developers and tasks using dashboards and feeds. Proceedings of the 32nd ACM/IEEE International Conference on Software Engineering - Volume 1. p. 365-374. ACM, New York, NY, USA (2010).

15. Siadaty, M., Jovanovic, J., Pata, K., Holocher-Ertl, T., Gasevic, D., Milikic, N.: A Semantic Web-enabled Tool for Self-Regulated Learning in the Workplace. 11th IEEE International Conference on Advanced Learning Technologies (ICALT). p. 66-70. IEEE (2011).

16. Scheffel, M., Wolpers, M., Beer, F.: Analyzing Contextualized Attention Metadata with Rough Set Methodologies to Support Self-regulated Learning. IEEE 10th International Conference on Advanced Learning Technologies (ICALT). p. 125-129. IEEE (2010).

17. Kuo, C.-H., Tsai, M.-H., Kang, S.-C.: A framework of information visualization for multi-system construction. Automation in Construction. 20, 247-262 (2011).

18. Moos, D.., Azevedo, J.: Monitoring, planning, and self-efficacy during learning with hypermedia: The impact of conceptual scaffolds. Computers in Human Behavior. 24, 1686-1706 (2008). 